\title{
Studies on Mechanical and Dielectric Properties of L-Phenylalanine Benzoic Acid Single Crystal for NLO Applications
}

\author{
S. Suresh, ${ }^{1}$ P. Mand, ${ }^{2}$ and K. Anand ${ }^{3}$ \\ ${ }^{1}$ Department of Physics, Loyola College, Chennai 600 034, India \\ ${ }^{2}$ Department of Physics, Hindustan Institute of Technology, Padur, Chennai 603 103, India \\ ${ }^{3}$ Department of Physics, Manakula Vinayagar Institute of Technology, Pudhucherry 605 107, India
}

Correspondence should be addressed to S. Suresh; sureshsagadevan@yahoo.co.in

Received 3 March 2012; Accepted 10 October 2012

Academic Editor: Ewa Schab-Balcerzak

Copyright (C) 2013 S. Suresh et al. This is an open access article distributed under the Creative Commons Attribution License, which permits unrestricted use, distribution, and reproduction in any medium, provided the original work is properly cited.

\begin{abstract}
Nonlinear optics (NLO) materials have a significant impact on laser technology, optical communication, optical storage technology, and electrooptic modulation. Nonlinear optical single crystal of L-phenylalanine benzoic acid has been grown by slow evaporation. The XRD analysis confirms that the crystal belongs to the monoclinic system with noncentrosymmetric space group P2 . Microhardness investigations are conducted on the grown crystals. The dielectric response of the sample is studied as a function of different frequencies and different temperatures. The photoconducting studies confirm that the title compound has negative photoconducting nature.
\end{abstract}

\section{Introduction}

In recent years, great efforts have been made to develop new organic, inorganic, and semiorganic nonlinear optical (NLO) crystals due to their widespread applications such as frequency conversion, high-speed information processing, optical communications, and optical data storage [1-3]. In the field of nonlinear optical crystal growth, amino acids play a vital role. Amino acids exhibit natural chiral properties and crystallize in the noncentrosymmetric space groups, which are an essential criterion for NLO applications. Optically active amino acids show high efficient optical second harmonic generation (SHG) and are promising candidates for laser and optical communication technology. Since isometrically pure and optically active substances always meet the symmetry requirements for optical second harmonic generation, there is considerable variation in efficiency for the generation of SHG, ranging from almost zero to greater than that of potassium dihydrogen phosphate crystals. Crystals capable of generating second harmonics must have a unit cell with no centre of inversion and this requirement is met by the crystals of pure amino acids because these molecules themselves are asymmetric [4-6]. A number of Lhistidine compounds exhibiting the NLO behaviour, namely, L-histidine acetate [7], L-histidine chloride monohydrate [8], L-histidine tetrafluoroborate [9], L-histidine hydrochloride monohydrate [10], L-histidine hydrofluoride dihydrate [11], L-histidine bromide [12], and L-histidinium trichloroacetate [13], were reported earlier. The crystal growth and characterization of L-histidinium trifluoroacetate and Lhistidine nitrate were reported from this laboratory [14, 15], recently. In the present paper, attention is focused on the mechanical, dielectric, and photoconductivity properties of L-phenylalanine benzoic acid single crystals.

\section{Experimental Procedure}

L-Phenylalanine benzoic acid (LPBA) was synthesized from L-phenylalanine and benzoic acid taken in equimolar ratio $1: 1$. The calculated amount of the reactants was thoroughly dissolved in deionized water and stirred well using magnetic stirrer to ensure uniform temperature and concentration throughout the entire volume of the solution. The solution 


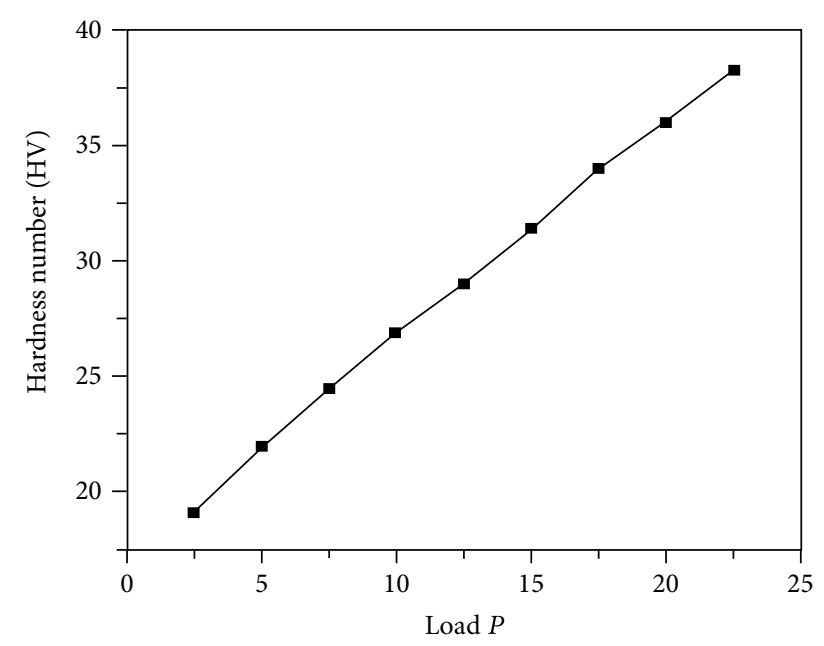

FIgURE 1: Vickers hardness versus load.

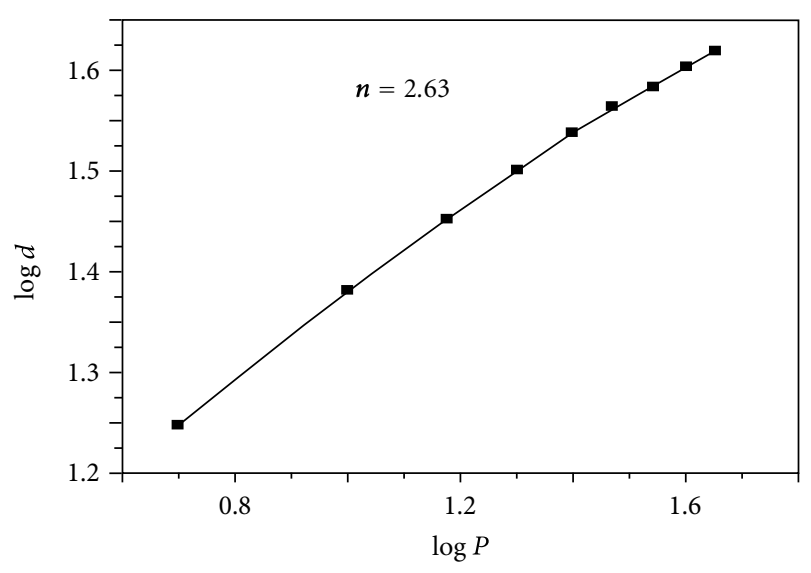

Figure 2: Plot of $\log P$ versus $\log d$.

was filtered and transferred to crystal growth vessels and crystallization was allowed to take place by slow evaporation under room temperature. A good colourless single crystal of LPBA was obtained in 30 days.

\section{Single X-Ray Diffraction}

From the XRD data, it is found that LPBA belongs to the monoclinic system with $a=5.42 \AA, b=7.44 \AA$ and $c=$ $17.80 \AA$, the space group being $\mathrm{P} 2_{1}$, and the volume of the system $V=717.5 \AA^{3}$. The results are very close in agreement with that of reported values [16].

\section{Mechanical Properties}

To find surface hardness of the as grown LPBA crystal, microhardness was measured from 5 to 25 gram load using HMV Microhardness tester. The Vickers hardness number $\left(H_{V}\right)$ was calculated using the standard formula:

$$
H_{V}=1.8544 \frac{P}{d^{2}},
$$

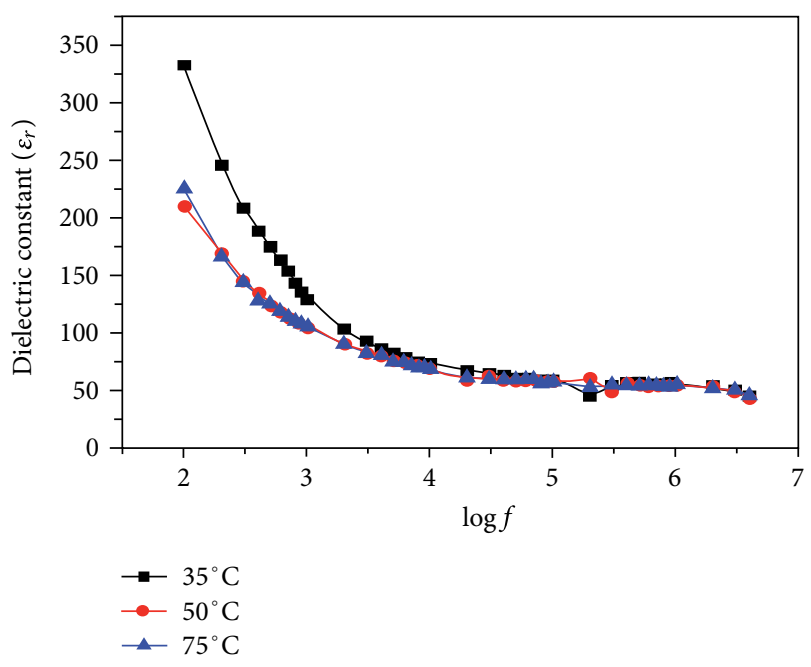

FIgURE 3: Variation of dielectric constant with frequency.

where $P$ is the applied load and $d$ is the mean diagonal length of the indentation. The trace is shown in Figure 1, which shows that the hardness increases with the increase of load. Meyer's index number was calculated from Meyer's law, which relates the load and indentation diagonal length as the following:

$$
\begin{gathered}
P=k d^{n}, \\
\log P=\log k+n \log d,
\end{gathered}
$$

where $k$ is the material constant and " $n$ " is Meyer's index. In order to find the value of " $n$," a graph is plotted for $\log P$ against $\log d$ (Figure 2) which gives a straight line. From the slope of the line Meyer's index number " $n$ " was calculated to be 2.63. According to Onitsch [17], " $n$ " lies between 1 and 1.6 for hard materials and is greater than 1.6 for soft materials [18]. The " $n$ " value observed in the present studies is around 2.63 suggesting that the grown LPBA crystal is a relatively soft material.

\section{Dielectric Studies}

The dielectric constant and the dielectric loss of the LPBA crystals were studied at different temperatures using HIOKI 3532 LCR HITESTER in the frequency region from $50 \mathrm{~Hz}$ to $5 \mathrm{MHz}$. The dielectric constant was measured as a function of frequency at different temperatures ranging from $35^{\circ} \mathrm{C}, 50^{\circ} \mathrm{C}$, and $75^{\circ} \mathrm{C}$ and is shown in Figure 3, while the corresponding dielectric losses are depicted in Figure 4. Figure 3 shows the plot of dielectric constant $(\varepsilon)$ versus $\log$ frequency for $35^{\circ} \mathrm{C}$, $50^{\circ} \mathrm{C}$, and $75^{\circ} \mathrm{C}$. It is seen that the value of dielectric constant is high in the lower-frequency region for all the temperatures and then it decreases with increase in frequency. The high value of dielectric constant at low-frequency region is attributed to space charge polarization due to charged lattice defects [19]. A graph is drawn between dielectric loss and log frequency for various temperatures $\left(35^{\circ} \mathrm{C}, 50^{\circ} \mathrm{C}\right.$, and $\left.75^{\circ} \mathrm{C}\right)$ and is shown in Figure 4. The low value of dielectric loss 


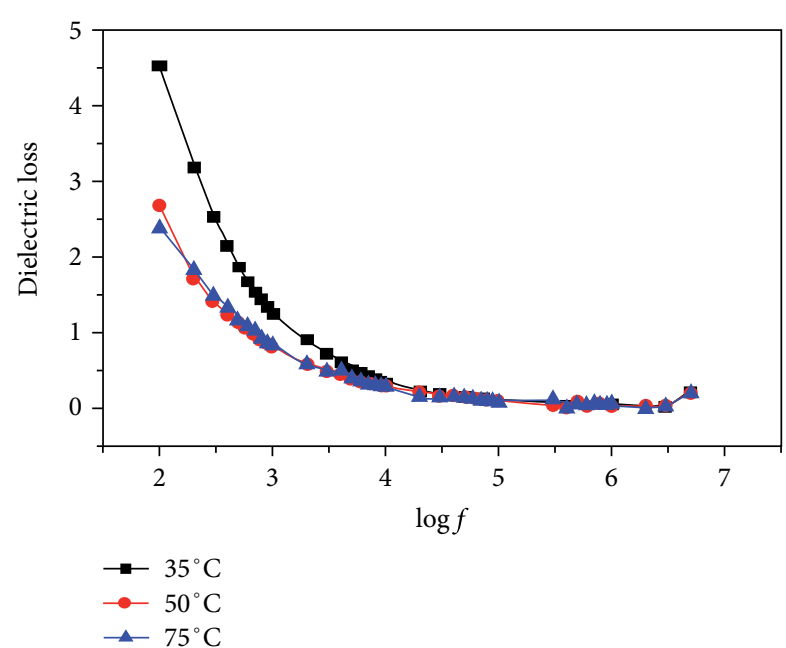

FIGURE 4: Variation of dielectric loss with frequency.

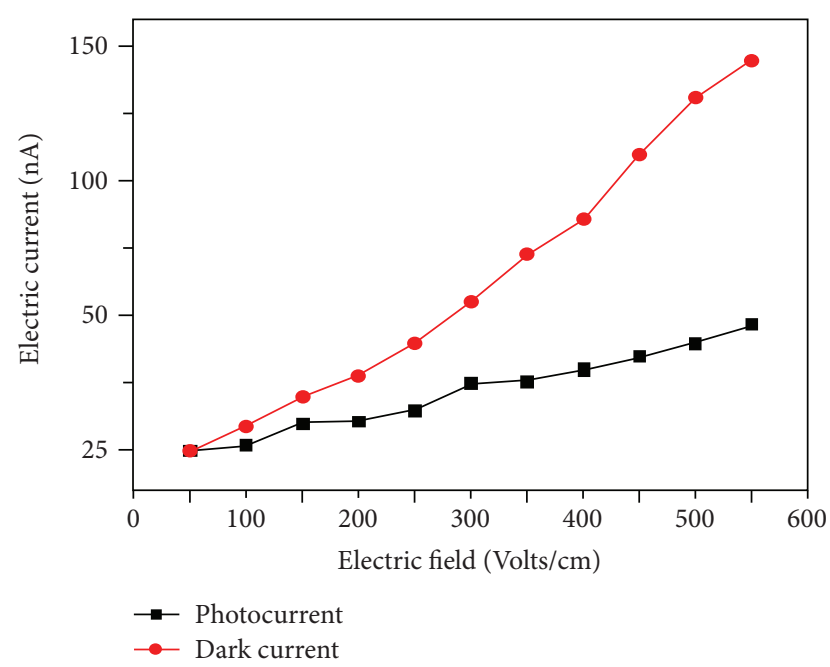

FIgURE 5: Field-dependent conductivity of LPBA single crystal.

at high frequency suggests that the grown crystals possess good optical quality. This parameter is of vital importance for nonlinear optical materials in their applications [20].

\section{Photoconductivity Studies}

Figure 5 shows the plot of dark current and photocurrent against electric field. It is observed from the graph that both dark current and photocurrent increase linearly with the applied electric field, but the photocurrent is less than the dark current which is termed as negative photoconductivity. The negative photoconductivity in a solid is due to the reduction in the number of charge carriers or their lifetime in the presence of radiation [21]. The decrease in mobile charge carriers during negative photoconductivity can be explained by the Stockman model [22]. The photocurrent was less than the dark current, signifying negative photoconducting nature.

\section{Conclusion}

Single crystals of LPBA are grown by slow evaporation technique in a period of 30 days. The structure of the grown crystal was confirmed by single crystal XRD analysis. The grown LPBA crystal is a relatively soft material from the investigations of microhardness. The dielectric studies were studied as a function of frequency. The variation of dielectric constant and dielectric loss was studied with varying frequency at different temperatures. Photoconductivity studies confirm that the crystal possesses a negative photoconducting nature.

\section{References}

[1] T. Sasaki and A. Yokotani, "Growth of large KDP crystals for laser fusion experiments," Journal of Crystal Growth, vol. 99, no. 1, pp. 820-826, 1990.

[2] F. Tsunesada, T. Iwai, T. Watanabe et al., "High-quality crystal growth of organic nonlinear optical crystal DAST," Journal of Crystal Growth, vol. 237-239, no. 1-4, pp. 2104-2106, 2002.

[3] Y. Zhang, H. Li, and Y. Che, "Growth and characterization of 1-histidine nitrate single crystal, a promising semiorganic NLO material," Materials Chemistry and Physics, vol. 108, no. 2-3, pp. 192-195, 2008.

[4] C. C. Frazier, M. P. Cockerhamn, E. A Chauchard, and C. $\mathrm{H}$. Lee, "Second-harmonic generation in aromatic organic compounds," Journal of the Optical Society of America, vol. 4, no. 11, pp. 1899-1903, 1987.

[5] P. Günter, Ch. Bosshard, K. Sutter et al., "2-cyclooctylamino-5nitropyridine, a new nonlinear optical crystal with orthorhombic symmetry," Applied Physics Letters, vol. 50, no. 9, pp. 486-488, 1987.

[6] D. Eimerl, S. Velsko, L. Davis, F. Wang, G. Loiacono, and G. Kennedy, "Deuterated L-arginine phosphate: a new efficient nonlinear crystal," IEEE Journal of Quantum Electronics, vol. 25, no. 2, pp. 179-193, 1989.

[7] J. Madhavan, S. Aruna, A. Anuradha, I. Vetha Potheher, K. Thamizharasan, and P. Sagayaraj, "Growth and characterization of a new nonlinear optical l-histidine acetate single crystals," Optical Materials, vol. 29, no. 9, pp. 1211-1216, 2007.

[8] A. B. Ahmed, H. Feki, Y. Abid, H. Boughzala, and C. Minot, "Crystal studies, vibrational spectra and non-linear optical properties of l-histidine chloride monohydrate," Spectrochimica Acta A, vol. 75, no. 1, pp. 293-298, 2010.

[9] M. D. Aggarwal, J. Choi, W. S. Wang et al., "Solution growth of a novel nonlinear optical material: L-histidine tetrafluoroborate," Journal of Crystal Growth, vol. 204, no. 1, pp. 179-182, 1999.

[10] J. Madhavan, S. Aruna, P. C. Thomas, M. Vimalan, and S. A. Rajasekar, "Growth and characterization of L-histidine hydrochloride monohydrate single crystals," Crystal Research and Technology, vol. 42, no. 1, pp. 59-64, 2007.

[11] J. Madhavan, S. Aruna, K. Prabha, J. P. Julius, G. P. Joseph, and P. Sagayaraj, "Growth and characterization of a novel NLO crystal 1-histidine hydrofluoride dihydrate (LHHF)," Journal of Crystal Growth, vol. 293, no. 2, pp. 409-414, 2006.

[12] A. B. Ahmed, H. Feki, Y. Abid, H. Boughzala, and A. Mlayah, "Structural, vibrational and theoretical studies of 1-histidine bromide," Journal of Molecular Structure, vol. 888, no. 1-3, pp. 180-186, 2008. 
[13] S. Gokul Raj, G. Ramesh Kumar, R. Mohan, B. Varghese, and R. Jayavel, "Crystal structure of single crystals of nonlinear optical 1-histidinium trichloroacetate," Journal of Molecular Structure, vol. 825, no. 1-3, pp. 158-164, 2006.

[14] S. A. Martin Britto Dhas, M. Suresh, G. Bhagavannarayana, and S. Natarajan, "Growth and characterization of a new organic non-linear optical (NLO) material: L-histidinium trifluoroacetate," The Open Crystallography Journal, vol. 1, pp. 46-50, 2008.

[15] S.A. Martin Britto Dhas and S. Natarajan, "Growth and characterization of two new NLO materials from the amino acid family: 1-Histidine nitrate and 1-Cysteine tartrate monohydrate," Optics Communications, vol. 281, no. 3, pp. 457-462, 2008.

[16] J. Suresh, R. V. Krishna Kumar, and S. Natarajan, "LPhenylalanine-benzoic acid (1/1)," Acta Crystallographica E, vol. 61, pp. 3625-3627, 2005.

[17] E. M. Onitsch, "The present status of testing the hardness of the materials," Microscope, vol. 95, p. 12, 1950.

[18] S. Karan and S. P. S. Gupta, "Vickers microhardness studies on solution-grown single crystals of magnesium sulphate heptahydrate," Materials Science and Engineering A, vol. 398, no. 1-2, pp. 198-203, 2005.

[19] C. P. Smyth, Dielectric Behaviour and Structure, Megraw Hill, New York, NY, USA, 1965.

[20] C. Balarew and R. Duhlev, "Application of the hard and soft acids and bases concept to explain ligand coordination in double salt structures," Journal of Solid State Chemistry, vol. 55, no. 1, pp. 1-6, 1984.

[21] R. H. Bube, Photoconductivity of Solids, John Wiley \& Sons, New York, NY, USA, 1960.

[22] V. N. Joshi, Photoconductivity, Marcel Dekker, New York, NY, USA, 1990. 

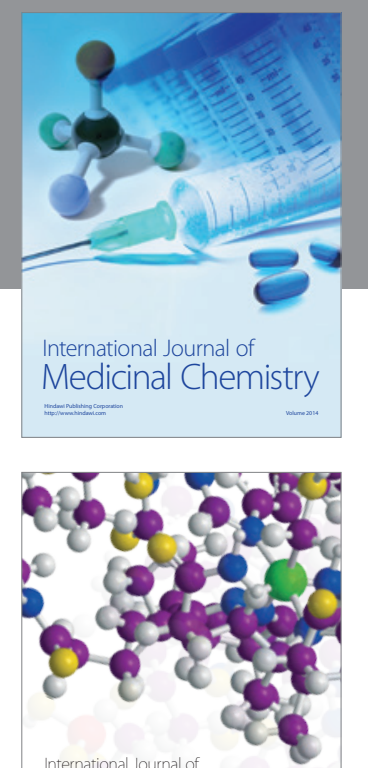

\section{Carbohydrate} Chemistry

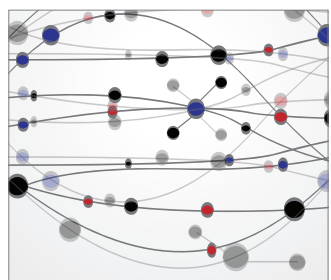

The Scientific World Journal
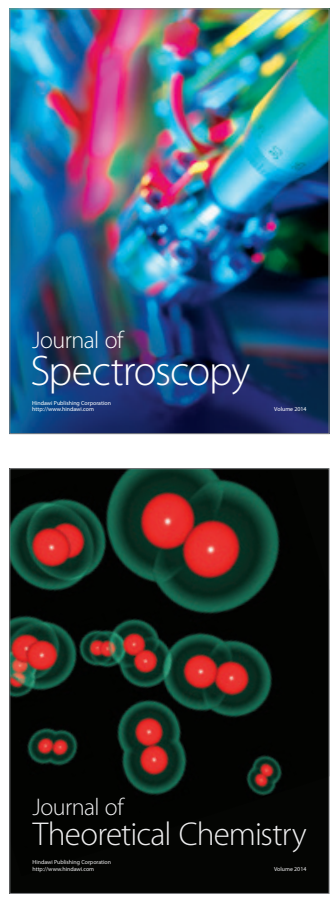
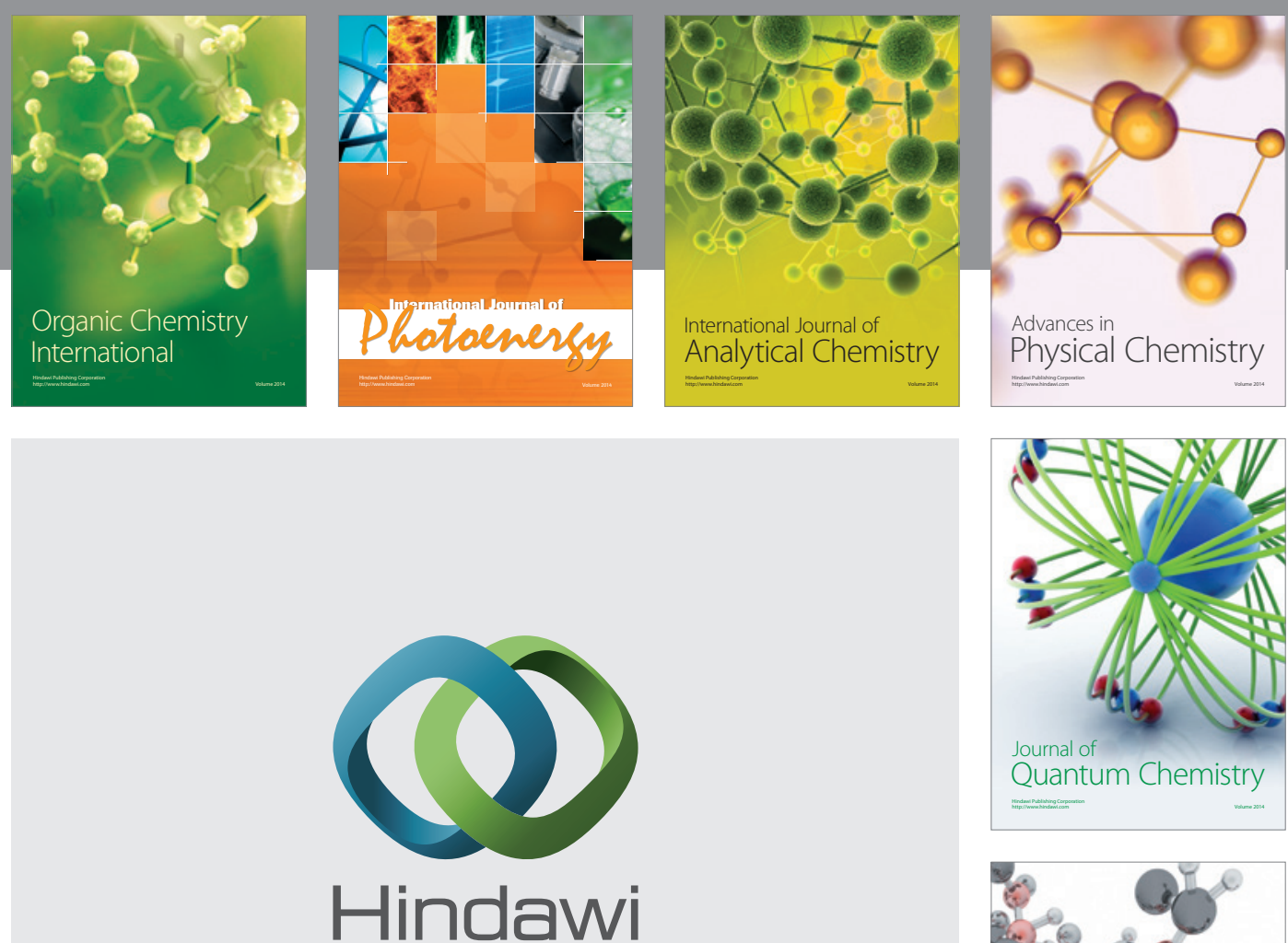

Submit your manuscripts at

http://www.hindawi.com

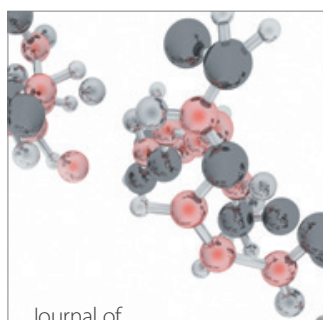

Analytical Methods

in Chemistry

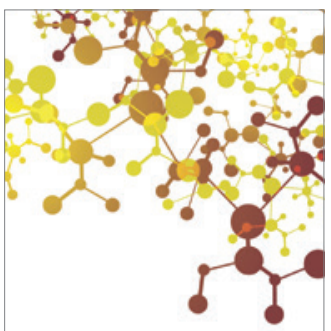

Journal of

Applied Chemistry

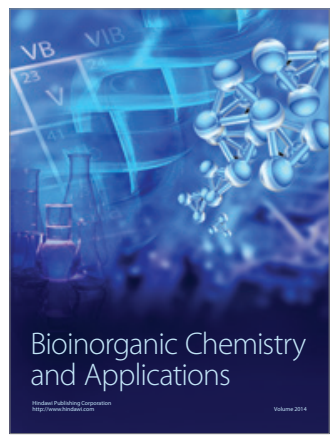

Inorganic Chemistry
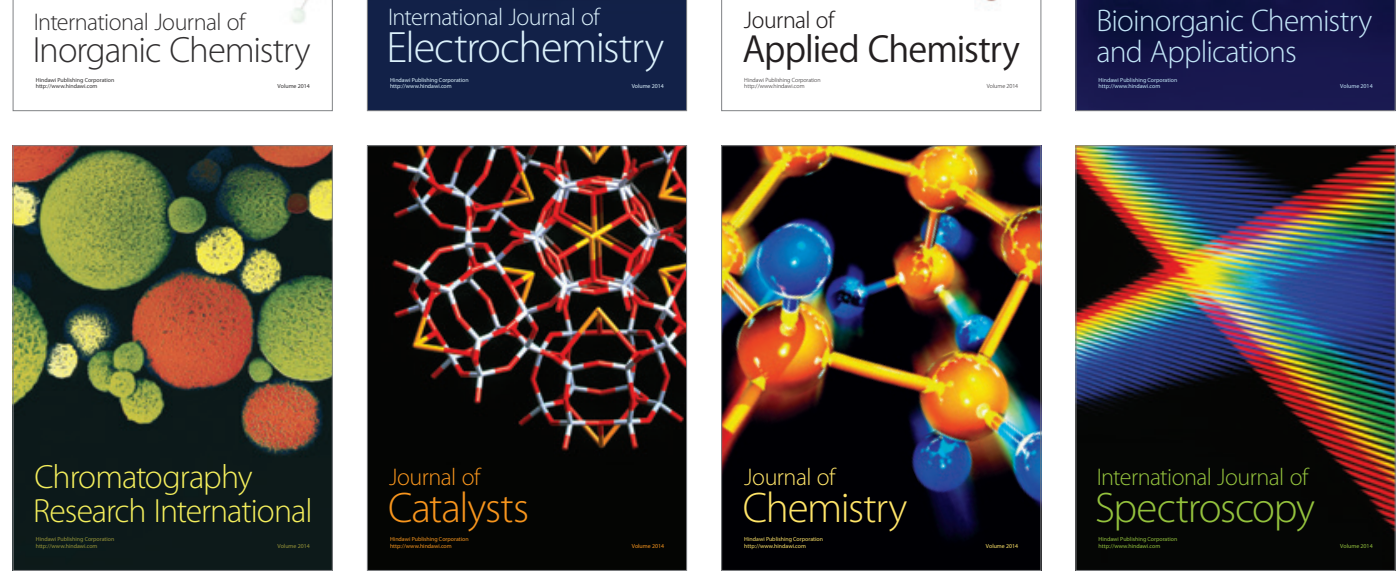